\title{
Autonomic Fog Computing: Towards Sustainable and Reliable Integration of Cloud \& Internet of Things
}

\author{
Maneet Kaur Bohmrah, Harjot Kaur
}

\begin{abstract}
With the growth of IoT based applications day by day huge volume of data is generated, which becomes a challenging issue for researchers. Fog computing is seem to be an effective solution for managing huge volume of data which is mainly security critical and time sensitive produced by IoT devices or sensors. In this paper we first present an integration of cloud and IoT as substantial number of application scenarios empowered by their Integration and discuss threats challenges \& existing solutions related to it. Followed by this, we discussed fog computing which supports the integration of cloud and IoT, further the issues related to fog has been explored. We proposed a concept of self-awareness in Fog computing termed as Autonomic Fog Computing. Autonomic fog computing is introducing the features of Self-management and hence increase the efficiency and enhance the overall system performance.
\end{abstract}

Index Terms: Cloud Computing, Internet of Things, CloudIoT, Self-management, Self-configuration, Fog Computing, and Autonomic Fog Computing.

\section{INTRODUCTION}

In the era of information revolution, data is the primary element and processing more data produce more value in data oriented businesses. With the growth of IoT based applications as nowadays they become a part of our life as from morning to evening a person is indulge with their smart phones, making a travel plan requires a smart app which presents the enough information about hotels and hot tourist visiting spots and the weather, health care applications, smart home, smart parking system etc. Hence with the increasing demands of the user, such applications are developed in rapid way and these are related to IoT. Moreover the data is generated rapidly and this large volume of data is send to the cloud data centers for processing by the IoT devices which increase the latency and security issues.

To resolve the issues of high-bandwidth, geographically scattered, latency and security concern applications, there is a requirement of computing technique that happen closer to connected devices. Hence concept of fog layer is introduced, with this first data is send to fog layer where filtration is performed and then to cloud and vice versa,

Revised Manuscript Received on June 22, 2019.

Maneet Kaur Bohmrah, Department of Computer Science \& Engineering in Khalsa College of Engineering \& Technology.

Dr. Harjot Kaur,Department of Computer Science \& Engineering of Guru Nanak Dev University. results in low latency. Fog computing fills the gap between the cloud and IoT devices by performing the computation, storage, communication on the network nodes which is near to the IoT devices. Fog computing faces number of challenges including energy consumption, latency, security many more due to day by day increasing of IoT devices. Fog computing enhances the capabilities of cloud computing and hence we explore the methodology which empowers the fog. We drive to an approach called autonomic computing, possess self-management features.

Autonomic cloud computing is also studied and analyzed that various issues such as reliability, failure, energy consumption were soughed out. Hence a concept of autonomic computing is also introduced with fog layer and this paper provides the motivation to introduce it.

\section{RESEARCH Methodology}

In this paper the following research methodology is followed as depicted in table 1. The complete paper is characterized as follow:

\section{A. Technology covered}

The focus of study of this paper is autonomic fog computing, before moving towards this proposed terminology we covered the various techniques such cloud computing, IoT, integration of Cloud \& IoT(cloudIoT) and Fog computing and more importantly the autonomic computing. With the study of these we came to know the requirement of autonomic fog computing.

\section{B. Challenges faced by Fog computing}

In this section e studied the various challenges faced by the fog computing and we analyze the field where autonomic fog computing performs well.

\section{Related work}

In this section we study the autonomic cloud computing and analyze how it achieve the QoS parameter such as resource utilization, energy consumption, CPU response, reliability, security and many more.

Moreover we studied the benefits of introducing the self-awareness in the fog layer.

\section{Proposed work}

In this section we proposed a terminology called Autonomic Fog Computing. This section is divided into following parts: overview, need of autonomic

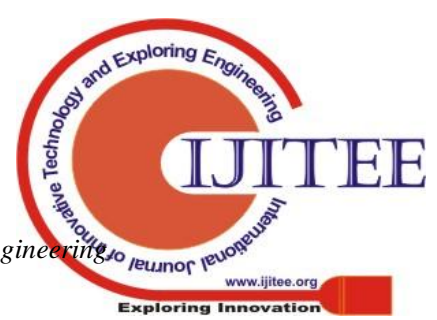


fog computing and it's processing.

Table I: Research methodology adopted in this paper.

\begin{tabular}{|c|c|c|}
\hline Major category & Sub category & $\begin{array}{l}\text { Sub-sub } \\
\text { category }\end{array}$ \\
\hline \multirow[t]{4}{*}{ Technology } & $\begin{array}{l}\text { Cloud } \\
\text { computing }\end{array}$ & $\begin{array}{l}\text { Overview } \\
\text { Benefits } \\
\text { Challenges }\end{array}$ \\
\hline & IoT & Overview \\
\hline & Cloud of things & $\begin{array}{l}\text { Overview } \\
\text { Challenges }\end{array}$ \\
\hline & Fog Computing & $\begin{array}{l}\text { Overview } \\
\text { Challenges }\end{array}$ \\
\hline Related survey & $\begin{array}{l}\text { Autonomic } \\
\text { Cloud } \\
\text { Computing }\end{array}$ & $\begin{array}{l}\text { Study of } \\
\text { various existing } \\
\text { techniques. }\end{array}$ \\
\hline Proposed work & $\begin{array}{l}\text { Autonomic Fog } \\
\text { Computing }\end{array}$ & $\begin{array}{c}\text { Concept } \\
\text { introduced }\end{array}$ \\
\hline
\end{tabular}

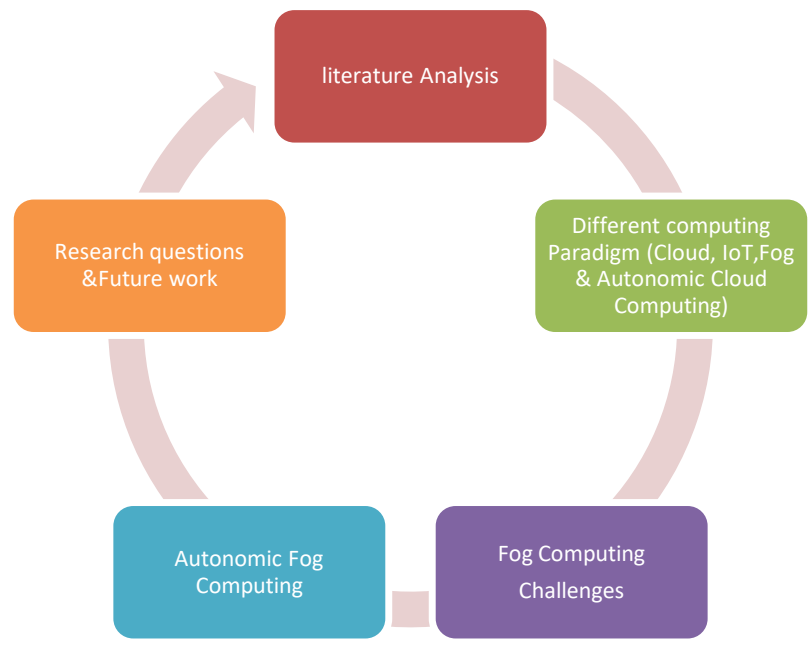

Fig. 1: Research methodoly

This paper is divided into mainly three sections: the first section is literature analysis which is followed by the study of various computing paradigm covers under the heading of motivation towards fog computing; second section covers fog computing and its challenges; and the most important section of this paper is the proposed terminology called Autonomic fog computing.

\section{Motivation Towards Fog COMPUTING}

This section focuses on the how the concept of fog computing introduce. Mainly discuss the parameters of cloud and IoT. Current research issues and also discuss the evolution of fog computing.

\section{A. Cloud Computing}

Cloud computing is defined as number of resources are available user pay as he uses. Resources are available in different forms such as infrastructure, platform and software. This follows the pay-as-you-go model which allows the users to conveniently use the resources and data management services and pay for the amount of resources they use [1].

\section{1) Cloud services}

The services provided by the cloud are mainly of three types infrastructure as a service, software as a service and platform as a service [2].Cloud services are the services provided by the cloud depicted in table 2 .

Table II: Types of services provided by the Cloud

\begin{tabular}{|l|l|l|}
\hline $\begin{array}{l}\text { Cloud } \\
\text { services }\end{array}$ & Meaning arture & Service Providers \\
\hline $\begin{array}{l}\text { Infrastructure a } \\
\text { service(IaaS) }\end{array}$ & $\begin{array}{l}\text { Allows users to } \\
\text { access IT } \\
\text { infrastructure } \\
\text { for processing, } \\
\text { storage and } \\
\text { networking } \\
\text { resources }\end{array}$ & $\begin{array}{l}\text { Amazon } \\
\text { services(AWS), } \\
\text { Microsoft Azure, } \\
\text { Google Compute } \\
\text { Engine(GCE) }\end{array}$ \\
\hline $\begin{array}{l}\text { Platform as a } \\
\text { service(PaaS) }\end{array}$ & $\begin{array}{l}\text { Allow user to } \\
\text { develop } \\
\text { software }\end{array}$ & $\begin{array}{l}\text { Apache Stratos, } \\
\text { Azure App services } \\
\text { or google App } \\
\text { Engine }\end{array}$ \\
\hline $\begin{array}{l}\text { Software as a } \\
\text { service(SaaS) }\end{array}$ & $\begin{array}{l}\text { Allow user to } \\
\text { host his } \\
\text { applications }\end{array}$ & $\begin{array}{l}\text { Google Apps or } \\
\text { web application }\end{array}$ \\
\hline
\end{tabular}

2) Current Research challenges

Various challenges faced by cloud computing. Some of them are below-

- Users access a large number of resources for pervasive computing

- Cloud based are applications are time consuming and hence not suitable for time sensitive applications.

- Day by day increasing number of devices connected with rapid growth of data hence managing such large volume of data makes the somewhere computation slow.

- High-bandwidth, geographically-scattered, typically low latency and security sensitive applications are in greater demand, hence such a technology required which brings computation, data processing and decision making closer to data generated IoT devices.

- Cloud resource provisioning is the main challenge for the cloud computing because demand of resources varying time to time hence this lead to either resource over provisioning or under -provisioning. Hence the amount of resources available in the data centers depend on the demand of cloud users as user pay only for the resources they used [3]

\section{B. Internet of Things}

Internet of things (IoT) describes as the group of things which can be either devices or sensors communicate with each other or exchange the information. IoT enables the communication of anything and anywhere. IoT devices are the considered users of cloud [5]. The data collected by the IoT sensors are send over the datacenters where the data is processed and the required

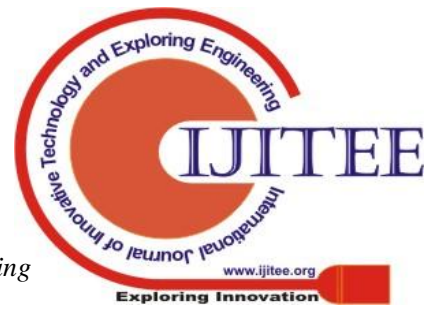


information is sent back to the user as depicted in figure 2 .

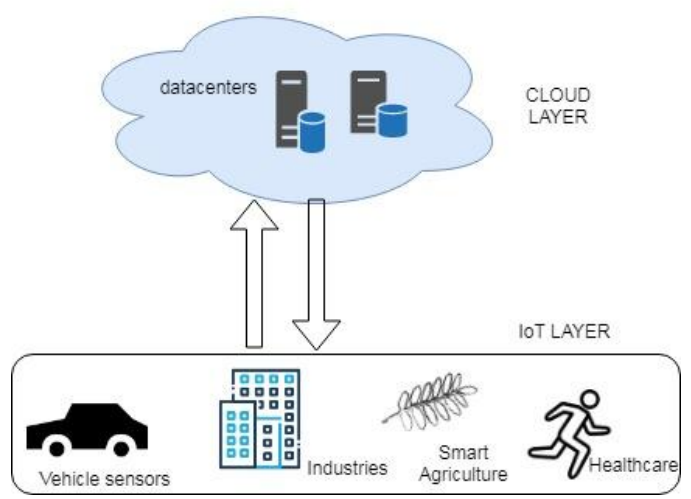

Fig. 2: Relation between cloud and IoT devices

\section{A. Challenges faced by IoT}

Various challenges faced by the IoT, we focused on some important issues such as:

- Standardization- lack of standards and protocols which authorized the IoT platform.

- Addressing \& Networking issues- million \& trillions of networking devices are connected, how to address such large number of devices.

- Security \& Privacy- how to authenticate the data.

- Energy efficiency- IoT devices are commonly smart phones or devices which posed small batteries hence battery drain is a problem, much of computation cannot be done on user side [4].

\section{Integration of Cloud \& IoT}

IoT is principally depicted by true little things, broadly dispersed with restricted calculation and capacity limit, which influences the unwavering quality, execution, security and protection. In the subsequent case, Cloud Computing has for all intents and purposes unlimited capacity and registering abilities, and settled a portion of the IoT issues [6]. The mix of two altogether different advances can be demonstrated recipient over the specific application situations, turns into a principle purpose behind proposing their incorporation by numerous scientists [7].

IoT can resolve the issue of its stockpiling with the utilization of for all intents and purposes boundless capacity limit of Cloud. Then again, distributed computing can resolve the issue of its degree with the use of IoT manage this present reality substance in an increasingly unique manner for conveying its new administrations. This propels the two advancements to consolidate and this new worldview call CloudIoT [8]. Table 3 depicts the qualities of CloudIoT as for the corresponding attributes of IoT and Cloud Computing.

Table III: Characteristics of CloudIoT w.r.t IoT and Cloud Computing

\begin{tabular}{|l|l|l|}
\hline IoT & Cloud Computing & CloudIoT \\
\hline IoT is & Cloud is Ubiquitous & CloudIoT is Ubiquitous \\
pervasive & (resources usable & $\begin{array}{l}\text { (resources accessible by the } \\
\text { (things placed }\end{array}$ \\
from everywhere) & things placed everywhere) \\
\hline
\end{tabular}

\begin{tabular}{|l|l|l|}
\hline everywhere) & & \\
\hline $\begin{array}{l}\text { Real world } \\
\text { things }\end{array}$ & Virtual Resources & Real world things \\
\hline $\begin{array}{l}\text { Restricted } \\
\text { Computational } \\
\text { Capabilities }\end{array}$ & $\begin{array}{l}\text { Virtually } \\
\text { non-restricted } \\
\text { computational } \\
\text { capabilities }\end{array}$ & $\begin{array}{l}\text { Non- restricted computational } \\
\text { capabilities (as computation } \\
\text { perform on the cloud rather on } \\
\text { the IoT devices) }\end{array}$ \\
\hline $\begin{array}{l}\text { Limited or } \\
\text { none storage } \\
\text { capabilities }\end{array}$ & $\begin{array}{l}\text { Virtually unlimited } \\
\text { storage capabilities }\end{array}$ & $\begin{array}{l}\text { Unlimited storage capabilities } \\
\text { (as data store on cloud, IoT } \\
\text { devices require small storage } \\
\text { only for its operation) }\end{array}$ \\
\hline $\begin{array}{l}\text { This uses } \\
\begin{array}{l}\text { Internet as a } \\
\text { point of } \\
\text { convergence }\end{array}\end{array}$ & $\begin{array}{l}\text { It uses Internet for } \\
\text { service delivery }\end{array}$ & $\begin{array}{l}\text { Uses internet for connecting to } \\
\text { cloud and for its own operations }\end{array}$ \\
\hline $\begin{array}{l}\text { Source of big } \\
\text { data }\end{array}$ & $\begin{array}{l}\text { Responsible } \\
\text { manage big data }\end{array}$ & $\begin{array}{l}\text { It is responsible for generator } \\
\text { and as well as manage big data }\end{array}$ \\
\hline
\end{tabular}

\section{1) Security issues related to Integration of IoT and}

Cloud Computing

With the integration of Cloud Computing and IoT one can discovered that Cloud Computing can fill a few holes of IoT to such an extent that constrained stockpiling and application over web. Then again IoT can fill a few holes of Cloud Computing with the end goal that restricted degree. This segment portrays the difficulties looked by the coordination of distributed computing and web of things. In this segment, we primarily talk about the highlights of CloudIoT which we characterized based on highlight of Cloud Computing and IoT.

\section{- Association}

Number of interconnected IoT gadgets increments, henceforth the cooperation among the gadgets becomes progressively unpredictable and less human impedance. Aggressors effectively change different gadgets practices which have reliance relationship to accomplish their objective.

\section{- Diversity}

Various sorts of IoT gadgets interface firmly with the physical environment, associate with various stage subsequently make CloudIoT differing in nature. A major test to this is heterogeneity.

\section{- Intimacy}

As keen meters, wearable gadgets all the more broadly utilized, these gadgets gather our science data and every day exercises. Along these lines we portray this cozy connection among clients and IoT gadgets as "intimacy".

\section{- Unattended}

At the point when CloudIoT intended for mission basic applications, for example, implantable therapeutic gadgets, military sensors, which works for an extensive stretch of time without physical access or gadget not reachable because of gadget disappointment, such lengthy time span unattended status of IoT gadget is named as "Unattended". Dependability 
is the enormous test for such IoT gadgets.

\section{- Constrained}

Because of expense and physical conditions IoT gadgets predominantly sensors are little in size and along these lines have restricted assets and power supply. This constrained capacity can be upgraded with the augmentation of Cloud Computing called Fog Computing (as haze is a cloud shut to the ground

\section{- Myriad}

With the expanding number of devices associated with a network, storage, processing and accessing to this colossal measure of information is turned into a challenge. Consequently CloudIoT manages the huge measure of making it heap. IoT will be one of the primary wellsprings of huge information.

\section{- $\quad$ Effectiveness}

For the viable and effective working of CloudIoT, observing is fundamental for capacity planning, for overseeing assets, execution and security. CloudIoT is influenced by the volume, velocity and variety of IoT and thus observing is a test that can't be dismissed.

Table IV: describes the different security aspects, threats, challenges and existing solutions.

\begin{tabular}{|c|c|c|c|}
\hline & $\begin{array}{l}\text { service } \\
(\text { DoS) attack }\end{array}$ & & \\
\hline Myriad & $\begin{array}{l}\text { Checking } \\
\text { and } \\
\text { following of } \\
\text { frameworks } \\
\text { is } \\
\text { troublesome } \\
\text { with the } \\
\text { present size } \\
\text { of Big data } \\
\text { application }\end{array}$ & Big Data & $\begin{array}{l}\text { OpenIoT, } \\
\text { Analyze the data, } \\
\text { Enterprise data } \\
\text { enrichment with } \\
\text { web and social } \\
\text { media [13] }\end{array}$ \\
\hline Intimacy & $\begin{array}{l}\text { Information } \\
\text { streams sent } \\
\text { over the } \\
\text { public } \\
\text { network, } \\
\text { security spill }\end{array}$ & $\begin{array}{l}\text { Sensor } \\
\text { Networks }\end{array}$ & $\begin{array}{l}\text { Reliable stream } \\
\text { of sensor data, } \\
\text { dynamic } \\
\text { configuration } \\
\text { and } \\
\text { re-configuration } \\
\text { of sensors and } \\
\text { security [14] }\end{array}$ \\
\hline $\begin{array}{l}\text { Effectivene } \\
\text { ss }\end{array}$ & $\begin{array}{l}\text { Troubleshoot } \\
\text { ing }\end{array}$ & Monitoring & $\begin{array}{l}\text { Aneka, accurate } \\
\text { measures in an } \\
\text { environment } \\
\text { dominated by } \\
\text { virtualized } \\
\text { resource }\end{array}$ \\
\hline
\end{tabular}

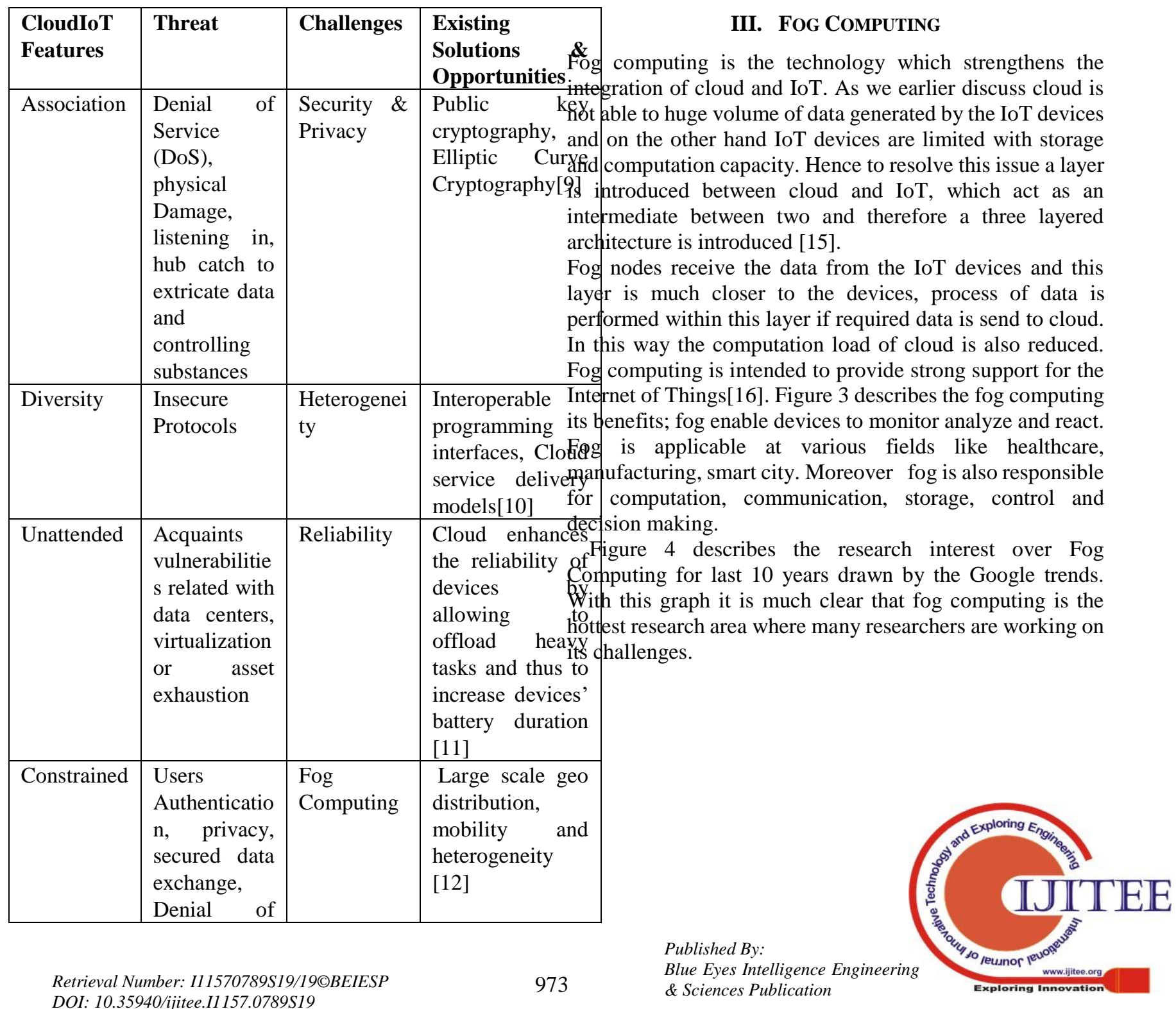




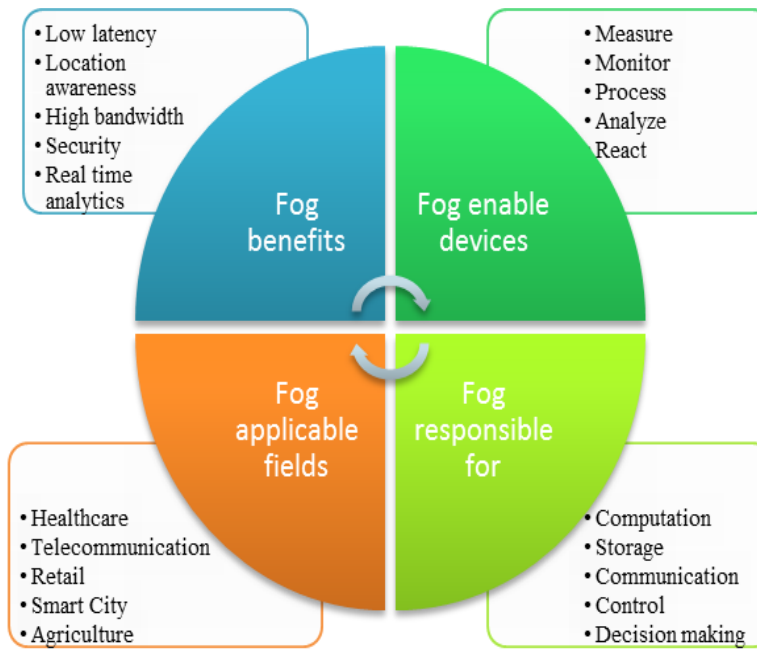

Fig.3: Overview of Fog Computing

Interest over time

- Cloud Computing - Fog computing

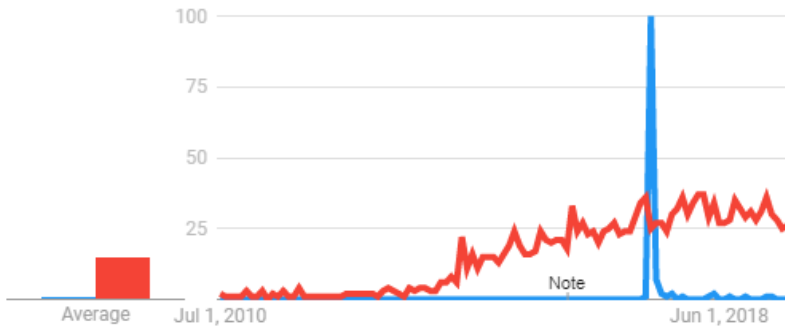

Fig. 4: Google trends graph depicts the research interest on cloud computing \& Fog for last 10 years.

\section{A. Need of Fog Computing}

Fog Computing increment the traditional cloud computing worldview to the edge of the framework, engaging the advancement of better applications or administrations. Fog processing is a much virtualized stage, provisioned computational power and capacity ability. The Fog will probably convey fantastic spilling to portable hubs, such as moving vehicles, through middle people and sections arranged fittingly, as, along parkways and tracks. Fog performs proficiently for applications with low inertness necessities, video spilling, gaming, enlarged reality, etc. For shrewd and effective correspondence, fogs are going to assume a significant job. [17]. Fog supports abundant features such as heterogeneity, mobility

support, location awareness, geographical distributed, low latency and so forth.

\section{B. How fog differs from cloud?}

Fog computing enhance the capability of cloud computing and resolve various issues of low latency, geographical distribution, low energy consumption and many more. Table 5 depicts the difference and makes clear distinction between fog and cloud.

Table V: Comparison between cloud and fog computing

\begin{tabular}{|c|c|}
\hline Cloud Computing & Fog Computing \\
\hline $\begin{array}{l}\text { Used for mainly data } \\
\text { storage }\end{array}$ & $\begin{array}{l}\text { IoT based applications, } \\
\text { healthcare \& smart city }\end{array}$ \\
\hline Far from users & Relatively close to the users \\
\hline Provide high latency & Provide low latency \\
\hline $\begin{array}{l}\text { High availability of } \\
\text { computing resources }\end{array}$ & $\begin{array}{c}\text { Relatively moderate } \\
\text { availability of computing } \\
\text { resources } \\
\end{array}$ \\
\hline High power consumption & Low power consumption \\
\hline Utilizes Large data centers & $\begin{array}{l}\text { Utilizes Small servers, } \\
\text { routers, gateways, set-top } \\
\text { boxes, access points }\end{array}$ \\
\hline $\begin{array}{l}\text { Huge space is required for } \\
\text { large numbers of } \\
\text { computing resources }\end{array}$ & $\begin{array}{l}\text { Less space is required for } \\
\text { hardware or resources }\end{array}$ \\
\hline $\begin{array}{l}\text { During the provision of } \\
\text { cloud service device should } \\
\text { be connected to the } \\
\text { internet. }\end{array}$ & $\begin{array}{l}\text { Fog services can work with } \\
\text { low or no internet } \\
\text { connectivity }\end{array}$ \\
\hline $\begin{array}{l}\text { Cloud accessed through the } \\
\text { network core }\end{array}$ & $\begin{array}{c}\text { Fog accessed from the } \\
\text { connected device at the edge } \\
\text { of the network to the network } \\
\text { core }\end{array}$ \\
\hline $\begin{array}{l}\text { Due to high latency cloud } \\
\text { is not suitable for time } \\
\text { sensitive applications }\end{array}$ & $\begin{array}{l}\text { Fog computing is suitable for } \\
\text { time sensitive applications }\end{array}$ \\
\hline
\end{tabular}

\section{Relation between fog, cloud and IoT}

Fog computing acquainted with satisfy the requests of constant IoT applications which are broadly dispersed. As the quantity of IoT clients expanded step by step the essentials for building up and keeping up such a colossal system is likewise quickly expanding. Mist processing gets an answer for high idleness administration conveyance, unseemly use of assets and non-uniform condition. As cloud administrations are a lot nearer to the IoT gadgets by presenting the mist layer. With the generally developing system mist likewise experiences different issues and difficulties of inactivity, asset usage and the difficulties because of security are winding up more pervasive than the past.

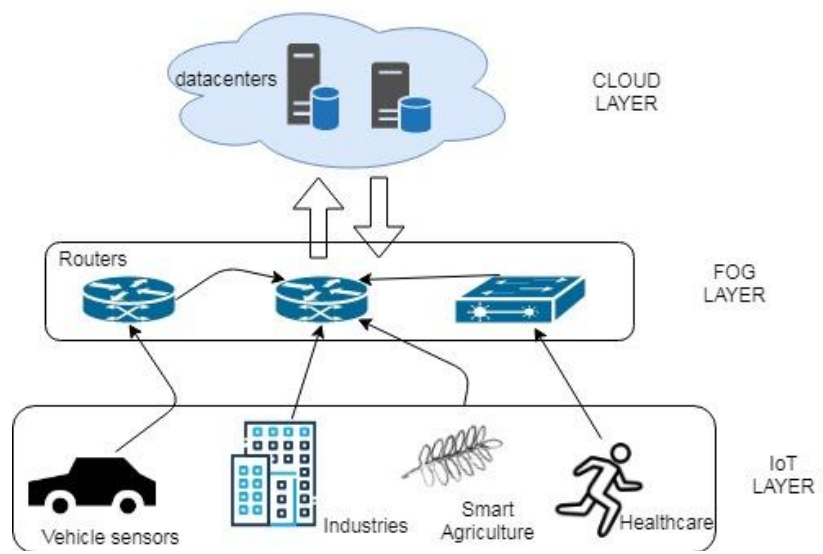

Fig.5: Relation between cloud, fog and IoT.

D. Challenges faced by fog computing

a) Issue of security and dependability: Because of heterogeneous and appropriated mist figuring

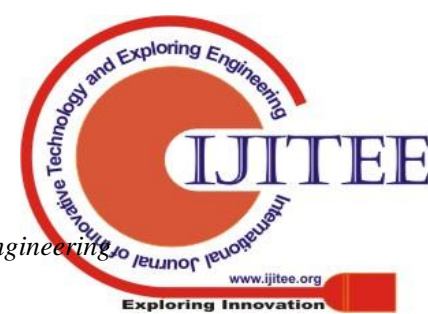


it is difficult to consolidate security conventions. Confirmation and approvals at different elements of haze hubs are one of the key security issues. Arrangement of a believed outsider and Public-Key Infrastructure depend on verification arrangements which can give security to haze gadgets. To diminish approval cost, rebel gadgets can be recognized utilizing estimation based methods. Unwavering quality or trustworthiness is one of the major issues since haze processing is included a sweeping number of geologically scattered gadgets. Unwavering quality conventions for sensor systems could use if there should arise an occurrence of the mistake of a cloud application, administration stage, system, and individual sensors.

b) Issue of Energy consumption and Latency: Mist condition involves incalculable haze hubs which are topographical scattered and handling information use enough vitality than fused cloud condition, from now on it is a significant research issue. Existing exploration declared that haze hubs are progressively talented to reduce inertness when contrasted with the cloud by experiencing a little bigger vitality usage in the midst of the execution of cloud-based applications. In a mist registering framework, the exchange off among postponement and power utilization is a potential research an area.

c) Issue of Resource utilization and Quality of Service: fog contraptions gangs' extra computational and capacity control, yet very little fit to create the accessibility of assets as looked at the cloud. In this way, a gainful asset the board strategy is required to bargain the application demands in an auspicious manner. One answer for this issue is exact forecast of benefit use by customer application should be foreseen decisively early, so appropriate usage of assets can be conceivable. What's more, existing asset the executive's frameworks in mist preparing consider execution time in a manner of speaking. In like manner; required strategy required to seek after the basic features of disseminated figuring in order to streamline the essential QoS parameters, for instance, execution time, vitality use and system framework use.

d) Issue of depository and processing: As the information are divided and put away crosswise over various areas, consequently hard to ensure information respectability and builds the danger of assaults. To decrease the danger of information spillage and the board overhead a client confided in outsider TPA (outsider evaluator) is included. Security of the outsider is itself an issue. Calculation undertaking is relocated from the cloud to mist hubs; it is required to again a trust between mist hubs and end gadgets, particularly without confided in outsider security.

\section{E. Fog is responsible forSustainable and Reliable merging of cloud and IoT}

Sustainabilityin Fogfiguring streamlines it's monetary and natural impact all things considered. Be that as it may, the generally practical engineering of Fog registering is liable to numerous issues like affirmation of QoS, administration reusability, energyefficient asset the board and so on. Then again, dependability in Fog registering can be examined regarding consistency of Fog gestures, accessibility of elite administrations, verified connections, adaptation to internal failure and so on. In the current writing an extremely limited discourse towards feasible and solid Fog processing has been given. Further research here is exceedingly prescribed for the ideal execution of Fog processing.

\section{Autonomic Computing}

Autonomic processing is a self-sensible registering framework, and "autonomic" started from the organic territory. The human body works in an automatic way without human intercession. Autonomic frameworks are propelled by the natural framework (autonomic sensory system) that can without much of a stretch handle issues like vulnerability, heterogeneity, dynamism, flaws, etc. In light of human direction, autonomic frameworks keep the processing framework stable in unusual conditions and adjust rapidly in new natural conditions like programming and equipment disappointments. Because of the self-administration property of figuring frameworks, the unpredictability of the framework is additionally undetectable to the client. Similarly as the Autonomic Nervous System (ANS) controls the human body's capacities (breathing, assimilation, and so on.), autonomic frameworks control the working of processing frameworks and applications without the association of people [18].Figure 6 illustrates the interest over autonomic computing for last 10 years.

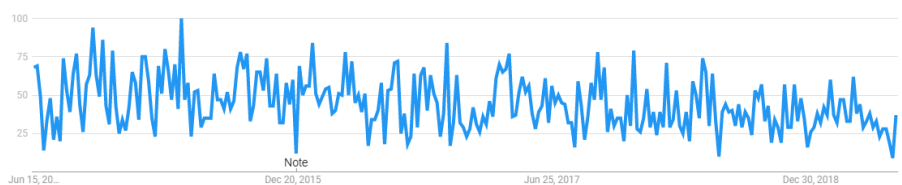

Fig.6: Google trend shows the research interest on Autonomic Computing for last 10 years

\section{A. Need of Autonomic Computing}

Autonomic registering presents the autonomic highlights which capable the framework to oversee itself called self-administration. Self-administration can be practiced by actualizing self-configuration, self-healing, self-advancement, and self-assurance. Autonomic registering advances the dynamic and versatile techniques which become compulsory for the current figuring innovations. Fog computing manages the heterogeneous world and fulfilling the QoS parameters such as reliability, scalability,

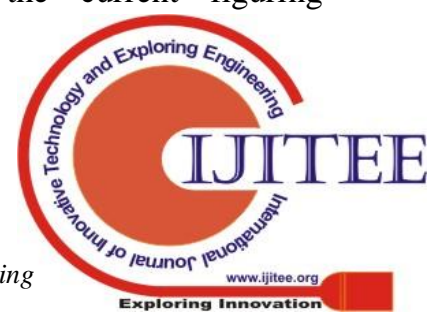


mobility, heterogeneity and so forth.

\section{B. Self-management properties of Autonomic Computing}

The core of autonomic figuring structures is self-organization, the objective of which is to free system executives from the subtleties of structure assignment and support, and to give customers a machine that continues running at pinnacle execution each moment of consistently. Figure 7 illustrates the basic properties of autonomic fog computing.

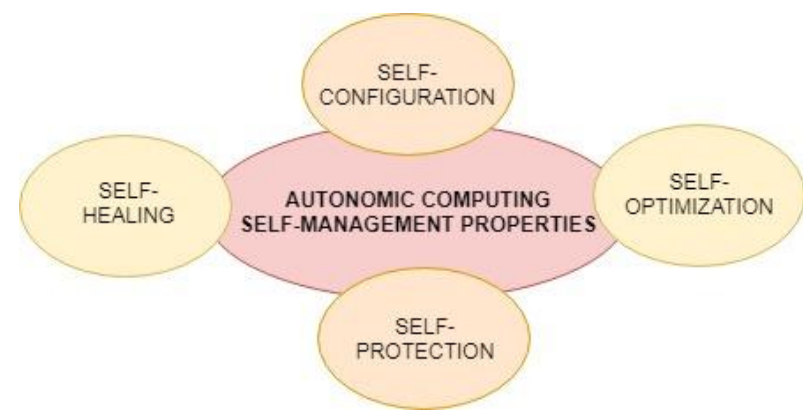

Fig. 7: Autonomic Computing \& its basic properties

1) Self-configuration: Autonomic frameworks will arrange themselves consequently in understanding the necessity or request. At the point when a part is presented, it will fuse itself flawlessly, and the remainder of the framework will adjust to its essence-much like another cell in the body or another individual in a populace. For instance, when another segment is brought into an autonomic bookkeeping framework, it will naturally find out about and consider the creation and setup of the framework. It will enroll itself and its capacities with the goal that different parts can either utilize it or alter their very own conduct fittingly.

2) Self-optimization; Autonomic frameworks will consistently look for approaches to improve their activity, recognizing and holding onto chances to make themselves increasingly proficient in execution or cost. Similarly as muscles become more grounded through exercise and the cerebrum changes its hardware during learning, autonomic frameworks will screen, explore different avenues regarding, and tune their own parameters and will figure out how to settle on proper decisions about keeping capacities or redistributing them. They will proactively try to overhaul their capacity by finding, confirming, and applying the most recent updates.

3) Self-healing: Autonomic processing frameworks will distinguish, analyze, and fix restricted issues coming about because of bugs or disappointments in programming and equipment. Utilizing learning about the framework arrangement, an issue conclusion segment (in light of a Bayesian system, for instance) would break down data from $\log$ records, conceivably enhanced with information from extra screens that it has mentioned. The framework would then match the finding against realized programming patches (or alarm a human software engineer if there are none), introduce the fitting patch, and retest.

4) Self- protection: Autonomic frameworks will act naturally ensuring in two detects. They will safeguard the framework all in all against enormous scale, related issues emerging from malevolent assaults or falling disappointments that stay uncorrected independent from anyone else mending measures. They additionally will foresee issues dependent on early reports from sensors and find a way to stay away from or moderate them [19].

\section{Autonomic Cloud Computing}

Autonomic frameworks dependent on QoS parameters are roused by organic frameworks that can without much of a stretch handle issues like vulnerability, heterogeneity, dynamism, deficiencies, etc. The objective of autonomic frameworks is to execute an application inside a due date by satisfying QoS necessities as portrayed by clients with least unpredictability. Autonomic processing frameworks are fundamentally enlivened from the ANS of people. The ANS has the capacity to manage all circumstances powerfully and deal with these circumstances in an unusual situation. As the ANS controls the human body's capacities (breathing, assimilation, and so forth.), Autonomic Cloud Computing Systems (ACCSs) control the working of cloud-based frameworks and applications without the association of people. Like the ANS, ACCSs check, screen, and react as per the circumstance, for example, self-recuperating, self-securing, self-arranging, and self-enhancing.

Numerous techniques which are published for introducing the autonomic features in cloud computing is illustrated as follows:

In 2010, Chen G et al. Proposed a method called SHelp reported as a naturally self-recuperating framework for various applications running in a virtual machine condition. In this methodology, creator build a system through which an application can be recuperated from the shortcoming if some other application is experienced a similar deficiency. This system logs the data of shortcomings and when some flaw happens whose fix is spared in the log then application recoups itself utilizing the logged data consequently a self-mending property of self-administration is accomplished. Dependability, vitality and reaction time are the few QoS parameters which are happy with this methodology [21].

In 2012, Lama P. et al proposed a strategy called AROMA, a system that motorizes the apportioning of heterogeneous Cloud resources and game plan of Hadoop parameters for achieving nature of organization destinations while constraining the realized cost. It keeps an eye on the tremendous trial of provisioning unrehearsed livelihoods that have execution due dates in Clouds through a novel two-organize AI and streamlining framework. Its specific focus is an assistance vector machine based execution show that enables the joining of various pieces of advantage provisioning and auto-design of Hadoop occupations. It acclimates to uniquely delegated occupations by effectively planning their benefit use signature with as of late executed livelihoods and choosing provisioning decisions in like way. They execute AROMA as an electronic work provisioning structure for Hadoop MapReduce. It results exhibit

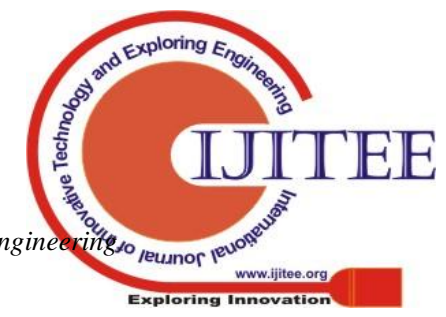


AROMA's practicality in giving execution affirmation of different Hadoop benchmark occupations while constraining the cost of Cloud resource use [22].

In 2013, Yuan et al proposed an engineering based self-assurance approach in this methodology a design based model is made called Architectural-level Mining Of Undesired conduct (Armor) gives a stage to client to play out its questions and the framework quietly screens the conduct of tasks executed and with this checking it can get the dangers and even the insider assaults. This methodology likewise $\log$ s the total preparing which is later on utilized in recuperation and henceforth accomplishing the self-insurance. In 2013, Kanter V. et al proposed COCCUS a deliberate structure for cost-careful request execution, adaptable inquiry charge, and progression of cloud data organizations. The client can set their inquiries close by their execution tendencies and spending prerequisites, while COCCUS adaptively chooses request charge and administers discretionary data structures as shown by various financial courses of action. The customers are engaged to set financial courses of action and execute diverse extraordinary jobs that need to be done through an extensive graphical UI. COCCUS's adaptability is shown using consistent diagrams depicting various key execution estimations [23].

In 2014 Chopra et al proposed a novel approach called SHAPE which gives oneself mending and self-assurance from different kinds of inside and outer assaults. The proposed method is fundamentally centered on security as this is one of the major QoS parameters which ought to be accomplished somewhat and issues identified with security expanded with the unpredictable and heterogeneous conduct of supporting system. It ensures equipment, system, and application from disappointments and gives protection from Denial of Service, Remote to nearby, User to Local assaults, and looking at issues. SHAPE is executed and surveyed against various standard estimations [24].

In 2016, Singh et al. proposed essentialness beneficial autonomic cloud system named as Self-Optimization of Cloud Computing Energy-productive Resources (SOCCER), for imperativeness compelling booking of cloud resources in server farms. The proposed work accepts imperativeness as a Quality of Service (QoS) parameter and thusly redesigns the viability of cloud resources by decreasing essentialness usage. Proposed system performs better with respect to essentialness usage of cloud resources and utilizations these benefits preferably [20].

In 2017, Gill SS et al proposed a procedure called CHOPPER which is characterized as Configuring, Healing, Optimizing and Protecting Policy for Efficient Resource the board. It proffers self-arrangement of projects and assets, self-recuperating by managing quick blames, self-assurance against malevolent projects and self-advancement for progressively utilization of the asset. Proposed method works better with respect to cost, execution time, SLA encroachment, resource question and moreover, gives protection from ambushes. In 2017, Singh et al. proposed one more system to conquer the issue of SLA infringement, the method called as STAR which chiefly covers reducing SLA infringement rate for the capable movement of cloud organizations. The execution of the proposed methodology has been surveyed through cloud condition. The exploratory results demonstrate that STAR is capable in diminishing SLA infringement rate and in improving distinctive QoS parameters which effect compelling cloud advantage movement [25].

In 2018, Gill SS et al proposed a strategy called BULLET for proficient asset the executives' dependent on a swarm enhancement. As the assets are exceptionally dissipated, heterogeneous and questionable because of this the potential outcomes of accomplishing the better QoS parameters become low. The asset planning which deals with allotting right asset at the right time and accessibility of assets are the two principle challenges for cloud suppliers. The correct task of asset can be practiced with the assistance of streamlining calculations. The proposed strategy successfully diminishes execution cost, time and imperativeness uses close by various QoS parameters [26].

In 2019, Singh et al. proposed a strategy called self-arranging and self-recuperating of cloud-based assets (RADAR) which is centered around shrewd administration of assets in distributed computing and chiefly fulfills the two properties of self-administration that are self-setup by reconfigure the framework utilities and self-mending by recouping itself from framework accidents or disappointments. Radar additionally upgraded the nature of cloud administration by keeping up the dependability, execution cost and time parameters of QoS [27].

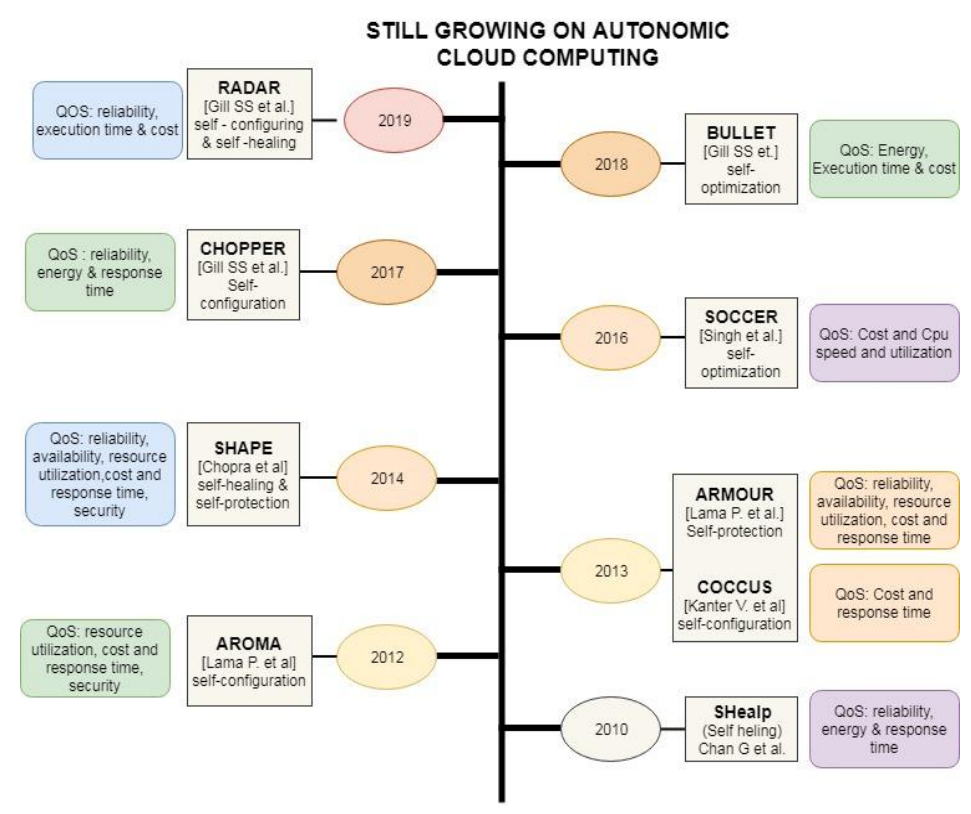

Fig.8: Autonomic Cloud Computing

\section{Proposed Work: Autonomic Fog Computing}

In fog processing, calculation is performed at the edge of the system at the entryway gadgets, decreasing transfer speed necessities, inertness, and the requirement for imparting information to the servers. Because

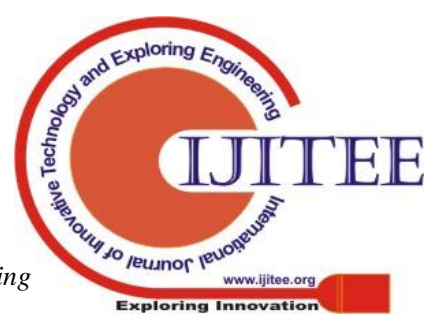


of its conveyed and limited design, haze figuring is a characteristic stage for an assortment of basic Internet of Things applications, for example, associated vehicles, shrewd lattices, savvy urban areas, and remote sensor and actuator networks. To that end, a few programming models and application structures have been produced for haze computing. However, in an exacting meaning of haze processing, the gadgets at the edges are not engaged with calculation but rather just in information obtaining, while the elucidation happens in the passage. Along these lines, organize delay and wasteful data transmission use are as yet present [28].

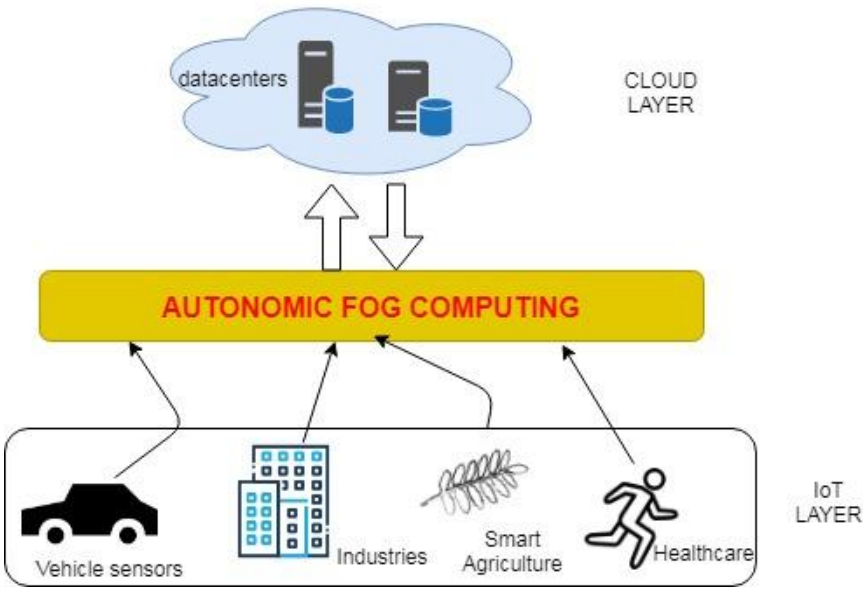

Fig. 9: Introduction of Autonomic Fog Computing

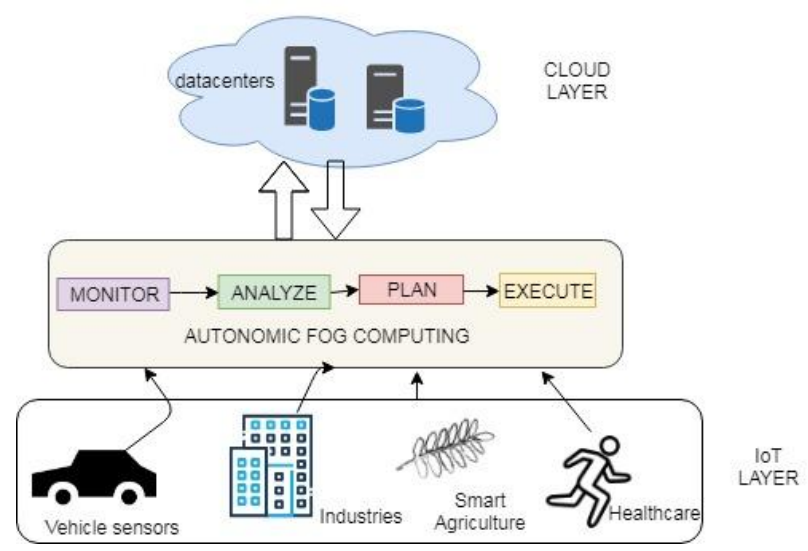

Fig.10: Process of Autonomic Fog Computing

Autonomic fog computing introduces in figure 10 which describes the overall function, this is mainly divides into four section: Monitor- this modules monitors the system; behavior. Analyze -this module figure out the changes which drives from the monitoring. Plan- this module decides the changes made and hence execute whatever the updating required would be performed.

\section{REFERENCES}

1. P. Mell, T. Grance, The nist definition of cloud computing, 2011

2. L.M. Vaquero, L. Rodero-Merino, J. Caceres, M. Linder, A break in the clouds: towards a cloud definition, ACM SIGCOMM Comput. Commun. Rev. vol. 39(1)2008 50-55.
3. T. Dillon, C. Wu, E. Chang, Cloud Compuing: issues and challenges, $24^{\text {th }}$ IEEE international conference on Advanced information Networking and Applications, IEEE, 2010, pp.1-6.

4. Commission of the European Communities, Early Challenges 1801, Regarding the "Internet of Things", 2008.

5. D. Giusto, A. Iera, G. Morabito, L. Atzori (Eds.), The Internet of Things, 1661 Springer, 2010. ISBN: 978-1-4419-1673-0.

6. J. Zhou, T. Leppanen, E. Harjula, M. Ylianttila, T. Ojala, C. Yu. H. Jin Cloudthings: A common architecture for integrating the internet of things and cloud computing, in: CSCWD, IEEE, 2013.

7. H. C. Chao, internet of things and cloud computing for future Internet,Ubiquitous Intelligence and Computing, in: Lecture Notes in Computer science, 2011.

8. A. Botta, W. de Donato, V. Persico, A. Pescape, Integration of Cloud Computing and Internet of Things: A survey, 0167-739X, Elsevier 2015.

9. S.Sbashini, V. Kavitha, A survey on security issues in service delivery models of cloud computing, J. Netw. Comput. Appl. vol. 34(1) 2011 pp $1-11$.

10. N. Grozev, R. Buyya, Inter-Cloud architectures and application brokering: survey, Soft-pract, Exp.vol. 44(3) 2014 pp 369-390.

11. W. He. G. Yan, L. D. Xu, Developing vehicular data cloud services in the iot environment, IEEE Trans. Ind. Inf.vol. 10(2)(2014)1587-1595.

12. Y.-K.Ji, Y,-I. Kim, S.Park, Big Data summarization using semantic feature for IoT on Cloud, 2014.

13. F. Zhao, Sensors meet the cloud: planetary -scale distributed sensing and decision making in: cognitive informatics(ICCI), $9^{\text {th }}$ IEEE international conference, IEEE,2010, p.998.

14. G. Aceto, A. Botta, W. de Donato, A.Pescape, Cloud monitoring: A survey, Comput. Netw. vol. 57(9) (2013)2093-2115.

15. L. M. Vaquero, L. Rodero-Merino, Finding Your Way in the Fog: Towards a Comprehensive Definition of Fog Computing, SIGCOMM Comput. Commun. Rev.vol. 44 (5) (2014) 27-32. doi:10.1145/2677046.2677052

16. F. Bonomi, R. Milito, J. Zhu, S. Addepalli, Fog Computing and its Role in the Internet of Things, Proceedings of the 1st Edition of the MCC Workshop on Mobile Cloud Computing, 2012, pp. 13-16. doi:10.1145/2342509.2342513

17. T. H. Luan, L. Gao, Z. Li, Y. Xiang, L. Sun, Fog Computing: Focusing on Mobile Users at the Edge. Preprint, available online arXiv:1502.01815.

18. Parashar M, Hariri S. Autonomic computing: an overview, up 2004. J.-P. Bana^tre (ed). LNCS, Springer Verlag, vol. 3566, 2005,pp. 247-259.

19. Kephart J, Chess D.The vision of autonomic computing. IEEE Comput. vol. 36, 2003, pp.41-50.

20. Singh S, Chana I, Singh, Buyya R. SOCCER: self-optimization of energy-efficient cloud resources. ClustComput. vol. 19(4), 2016, pp. 1787-1800.

21. Chen G, Jin H, Zou D, Zhou BB, Qiang, Hu G. SHelp: automatic self-healing for multiple application instances in a virtual machine environment. IEEE International Conference on Cluster Computing, 2010.

22. Lama P, Zhou X. AROMA: automated resource allocation and configuration of MapReduce environment in the cloud. Proceedings of the $9^{\text {th }}$ International Conference on Autonomic Computing, 2012.

23. Konstantinou I, Kanter V, Tsoumakos D, Koziris N. COCCUS: self-configured cost-based query services in the cloud. Proceedings of the 2013 ACM SIGMOD International Conference on Management of Data, 2013.

24. Inderpreet Chopra and Maninder Singh. 2014. SHAPE—an approach for self-healing and self-protection in complex distributed networks. $J$. Supercomp, vol.67(2), 2014, pp. 585-613. DOI:http://dx.doi.org/10.1007/s11227-013-1019-3

25. Gill SS, Chana I, Singh, Buyya R. CHOPPER: an intelligent QoS-aware autonomic resource management approach for cloud computing. Clust Comput.2017, pp. 1-39. https://doi.org/10.1007/s10586-017-1040-z.

26. Gill SS, Buyya R, Chana I, Singh, Abraham A. BULLET: particle swarm optimization based scheduling technique for provisioned cloud resources.JNetwSystManag.vol. 26(2), 2018, pp.361-400.

27. Gill SS, Buyya R, Chana I, Singh, RADAR: Self-configuring and self-healing resourcemanagement for enhancing quality of cloud servicesConcurrency Computat Pract Exper. 2019; 31: e4834. 
wileyonlinelibrary.com/journal/cpe @2018 John Wiley \& Sons, Ltd. 1 of 29https://doi.org/10.1002/cpe.4834

28. Kaur, Maneet and Kaur, Harjot, Autonomic Computing for Sustainable and Reliable Fog Computing (February 23, 2019).

Proceedings of International Conference on Sustainable Computing in Science, Technology and Management (SUSCOM), 2019,pp. 26-28. Available

SSRN: https://ssrn.com/abstract=3363069 or http://dx.doi.org/10.213 9/ssrn.3363069

\section{AUTHORS PROFILE}

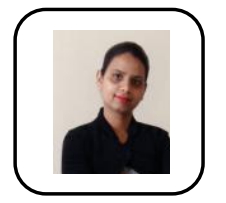

Maneet Kaur Bohmrah, Assistant Professor in Department of Computer Science \& Engineering in Khalsa College of Engineering \& Technologyfor last 7 years, received degree of Bachelors in Computer science \&engineering from Rajiv Gandhi Vishwavidhayalaya University, Bhopal in 2009and received degree of Master in Computer Science \& Engineering from Guru Nanak Dev University, Amritsar in 2015. Now pursuing Ph.D from Computer Science \& Engineering of Guru Nanak Dev University, Amritsar.

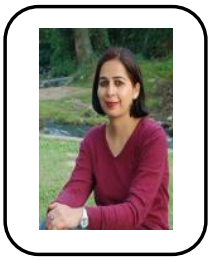

Dr. Harjot Kaurassistant Professor in Department of Computer Science \& Engineeringof Guru Nanak Dev University. She completed her Ph.D from Guru Nanak Dev University in year 2015. 